\title{
2D/3D echocardiographic determinants of left ventricular reverse remodelling after MitraClip implantation
}

\section{Sara Cimino ${ }^{1}$, Viviana Maestrini ${ }^{1}$, Donatella Cantisani ${ }^{1}$, Valentina Petronilli ${ }^{1}$, Domenico Filomena ${ }^{1}$, Massimo Mancone ${ }^{1}$, Gennaro Sardella ${ }^{1}$, Francesco Fedele ${ }^{1}$, Patrizio Lancellotti ${ }^{2}$, and Luciano Agati ${ }^{1}$}

1Department of Cardiovascular, Respiratory, Nephrological, Aenesthesiological and Geriatric Sciences "Sapienza" University of Rome, Policlinico Umberto I, Viale del Policlinico 155, 00161 Rome, Italy; and ${ }^{2}$ Department of Cardiology, GIGA Cardiovascular Sciences, Heart Valve Clinic, University of Liège Hospital, CHU Sart-Tilman, Avenue de L'Hòpital 1, 4000 Liège, Belgium

Received 23 June 2018; editorial decision 29 September 2018; accepted 4 October 2018; online publish-ahead-of-print 8 November 2018

Aims

The aim of this study was to describe incidence and determinants of left ventricular reverse remodelling ( $r$-LVR) at 6 months follow-up after MitraClip implantation in patients with secondary severe mitral regurgitation (MR) and reduced left ventricular ejection fraction (LVEF).

Methods

and results

Forty-five patients, undergoing MitralClip implantation with low ejection fraction and high surgical risk were enrolled in this study. Three of them died before the scheduled 6 months follow-up period and one patient had cardiac surgery due to MitraClip detachment. All patients underwent transthoracic 2D and 3D echocardiography before and 6 months after the procedure. A significant MR severity reduction and an improvement in New York Heart Association (NYHA) class were detected in all patients. The study population was divided in two groups according to the presence of $r$-LVR (51\%, $n=23$ patients) or not (non-rLVR group, 18 patients). Non-significant differences in $M R$ aetiology and number of clips implanted were found. Left ventricular reverse remodelling patients showed significant lower values of logistic EuroSCORE and STS score, left ventricular end-diastolic volume index (LVEDV/i), right ventricular end systolic area, and pulmonary artery systolic pressure (PASp) at baseline evaluation. At multivariable analysis, baseline PASp value resulted to be the only independent predictor of $r$-LVR [odds ratio $95 \%$ confidence interval 0.94 (0.89-0.99), $P=0.021]$. In $r$-LVR patients, a significant improvement in LVEF and global longitudinal strain and a reduction in left atrial volume index were detected after 6 months, whereas in non-rLVR subgroup a significant increase in both LVEDV/i and left ventricular end-systolic volume index was observed at follow-up.

Conclusion

Even if a reduction of MR was detected in all patients after MitralClip implant, our findings suggest that end-stage patients presenting with higher left ventricular volumes, logistic scores, and PASp may not benefit from the procedure at longer follow-up in terms of left ventricular function.

Keywords heart failure • mitral valve regurgitation - percutaneous edge-to-edge valve repair • MitraClip

\section{Introduction}

Mitral regurgitation (MR) is the second most prevalent valvular disease in Europe. The disorder commonly evolves insidiously over many years, causing progressive left atrial (LA) and left ventricular
(LV) dilatation and consequent deterioration of LV contractile function due to chronic volume overload. Despite optimal medical therapy, severe secondary MR confers a worse prognosis. ${ }^{1,2}$

Mitral valve (MV) surgery (repair or replacement) ${ }^{3}$ is the current standard of care for patients with severe symptomatic primary MR; it

* Corresponding author. Tel: +3906 49979048; Fax: +3906 49979060. E-mail: sara.cimino@uniroma1.it 
Table I Baseline characteristics

\begin{tabular}{lc}
\hline Parameters & Patients $(\mathbf{n}=\mathbf{4 5})$ \\
\hline Age (years) & $73 \pm 7.7$ \\
Logistic EuroSCORE & $13 \pm 8.2$ \\
STS score & $6 \pm 5.6$ \\
Male sex, $n$ (\%) & $22(48)$ \\
Diabetes, $n$ (\%) & $11(24)$ \\
Hypertension, $n$ (\%) & $36(80)$ \\
Dyslipidaemia, $n$ (\%) & $24(53)$ \\
Previous AMI, $n$ (\%) & $14(31)$ \\
Previous PCl, $n$ (\%) & $15(33)$ \\
Previous CABG, $n$ (\%) & $6(13)$ \\
CRF, $n$ (\%) & $12(26)$ \\
NYHA III-IV, $n$ (\%) & $45(100)$ \\
Nitrates, $n(\%)$ & $20(44)$ \\
ACE-inhibitors/ARBs, $n(\%)$ & $26(58)$ \\
Ivabradine, $n$ (\%) & $1(0.02)$ \\
Beta-blockers, $n$ (\%) & $42(93)$ \\
Anticoagulants, $n(\%)$ & $12(26)$ \\
Antiplatelets, $n$ (\%) & $24(53)$ \\
Antialdosterone, $n$ (\%) & $37(83)$ \\
Diuretics, $n(\%)$ & $45(100)$ \\
Pacemaker, $n$ (\%) & $12(26)$ \\
AF, $n$ (\%) & $10(22)$ \\
Non-ischaemic aetiology, $n(\%)$ & $29(65)$ \\
Ischaemic aetiology, $n(\%)$ & $16(35)$ \\
\hline
\end{tabular}

$A C E$, angiotensin converting enzyme; $A F$, atrial fibrillation; $A M I$, acute myocardial infarction; ARBs, angiotensin II receptor blockers; CABG, coronary artery bypass grafting; CRF, chronic renal failure; NYHA, New York Heart Association; PCl, percutaneous coronary intervention; STS, Society of Thoracic Surgery Score.

has been shown to result in potential reverse LA and LV remodelling ( $r$ LVR). ${ }^{4}$ However, due to the high operative risk, limited data are available about therapeutic benefits of MV surgery in patients with heart failure and secondary MR. Current guidelines only advocate a Class II indication for MV surgery in symptomatic patients with chronic severe secondary $M R$ and severely reduced LV ejection fraction (LVEF) $(<30 \%){ }^{3-5}$

The MitraClip device has evolved as a promising interventional tool for MV repair in severe MR., ${ }^{6,7}$ The first randomized controlled study (EVEREST II) demonstrated a superior safety of endovascular valve edge-to-edge repair when compared with MV surgery, with a similar improvement in clinical outcome. ${ }^{8,9}$ MitraClip might be a valid therapeutic option for selected high-risk surgical patients with severely reduced LV function. Several studies demonstrated encouraging data about clinical and safety results after MitraClip implantation in this high-risk subset of patients, however, it is yet to know whether the reduction in MR leads to $r$-LVR, and ultimately improved prognosis, in the long-term. We sought to evaluate the determinants of r-LVR at 6 months follow-up after MitraClip implantation.

\section{Methods}

\section{Study population}

From June 2014 to July 2017, 45 consecutive patients undergoing percutaneous MV repair with the MitraClip system were enrolled
Table 2 Echocardiographic parameters at baseline and at 6-month follow-up in the overall cohort of patients

\begin{tabular}{|c|c|c|c|}
\hline Parameters & $\begin{array}{l}\text { Baseline, } \\
\text { mean } \pm \text { SD }\end{array}$ & $\begin{array}{l}6 \text { months, } \\
\text { mean } \pm \text { SD }\end{array}$ & $P$-value \\
\hline Regurgitant volume $(\mathrm{mL})$ & $51 \pm 14.3$ & $27 \pm 8$ & $<0.001$ \\
\hline EROA $\left(\mathrm{cm}^{2}\right)$ & $0.37 \pm 0.15$ & $0.19 \pm 0.06$ & 0.023 \\
\hline Annulus diameter (mm) & $37 \pm 4.4$ & $35 \pm 3.7$ & 0.026 \\
\hline E wave $(\mathrm{cm} / \mathrm{s})$ & $117 \pm 49$ & $148 \pm 49$ & NS \\
\hline Septal e' $(\mathrm{cm} / \mathrm{s})$ & $5.1 \pm 1.5$ & $4.34 \pm 3.1$ & NS \\
\hline LVEF \% & $29 \pm 11$ & $29 \pm 12$ & NS \\
\hline LVEDV/i $\left(\mathrm{mL} / \mathrm{m}^{2}\right)$ & $96 \pm 24$ & $93 \pm 32$ & NS \\
\hline LVESV/i $\left(\mathrm{mL} / \mathrm{m}^{2}\right)$ & $68 \pm 25$ & $65 \pm 30$ & NS \\
\hline LA Vol/i $\left(\mathrm{mL} / \mathrm{m}^{2}\right)$ & $54 \pm 19$ & $49 \pm 19.3$ & NS \\
\hline RA Volli $\left(\mathrm{mL} / \mathrm{m}^{2}\right)$ & $41 \pm 22.9$ & $41 \pm 31$ & NS \\
\hline RV ED area $\left(\mathrm{cm}^{2}\right)$ & $17 \pm 4.7$ & $18 \pm 6.8$ & NS \\
\hline RV ES area $\left(\mathrm{cm}^{2}\right)$ & $11 \pm 3.8$ & $12 \pm 5.8$ & NS \\
\hline RV FAC \% & $36 \pm 8.6$ & $36 \pm 6$ & NS \\
\hline TAPSE (mm) & $20 \pm 3.6$ & $21 \pm 2.8$ & NS \\
\hline PASp $(\mathrm{mmHg})$ & $44 \pm 15.7$ & $44 \pm 14$ & NS \\
\hline GLS \% & $-6.4 \pm 3.5$ & $-7.3 \pm 3.15$ & NS \\
\hline
\end{tabular}

$E D$, end-diastolic; ES, end-systolic; EROA, effective regurgitant orifice area; FAC, fractional area change; GLS, global longitudinal strain; LA Vol/i, left atrium volume/index; LVEDV/i, left ventricular end-diastolic volume index; LVEF, left ventricular ejection fraction; LVESV/i, left ventricular end-systolic volume index; NS, not significant; PASp, pulmonary artery systolic pressure; RA Vol/i, right atrium volume/index; RV, right ventricle; SD, standard deviation; TAPSE, tricuspid annular plane excursion.

prospectively in this study. Inclusion criteria were: (i) a diagnosis of severe secondary MR; (ii) reduced LV function (<45\%); (iii) high surgical risk; and (iv) New York Heart Association (NYHA) Class III or IV. Patients with MV morphological properties that would make MitraClip implantation unlikely or unsuitable were excluded. ${ }^{9,10}$ The MitraClip procedure was explained to the patients, as well as alternative options (medical treatment or high-risk MV surgery). The 'Heart Team' evaluated patients and conventional surgery was excluded in case of excessive morbidity and mortality (high logistic EuroSCORE or STS score, or excessive comorbidities). ${ }^{9}$ The local ethics committee approved this study, and all patients provided written informed consent.

Patients were on optimized medical therapy and were treated with percutaneous angioplasty and stent implantation, implantable cardioverter defibrillator, and cardiac resynchronization therapy devices prior to MitraClip therapy, if clinically indicated. The baseline and follow-up functional status was assessed according to the NYHA criteria.

\section{Echocardiography}

All enrolled patients underwent transthoracic two- and threedimensional echocardiography (3DE) (Philips X5-1 Transducer, EPIQ7C) before and at 6 months after the procedure of percutaneous MV repair. The presence of MR at baseline was qualified by colour Doppler and quantified by the vena contracta width and the Proximal Isovelocity Surface Area method in accordance with the 


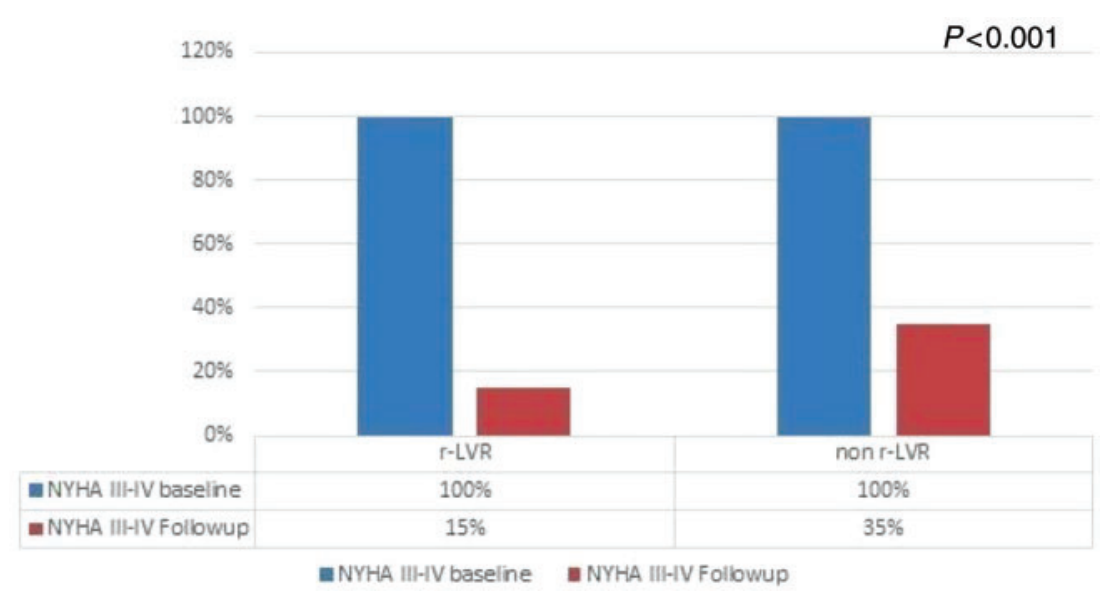

Figure I Percentage of NYHA Class III-IV class at baseline and at 6 months follow-up.

Table 3 Clinical and echocardiographic variables in r-LVR vs. non-rLVR patients at baseline

\begin{tabular}{|c|c|c|c|}
\hline Parameters & Non-rLVR $(n=18)$ & $r-\operatorname{LVR}(n=23)$ & $P$-value \\
\hline Age (years) & $74 \pm 6.4$ & $72 \pm 8.7$ & NS \\
\hline EuroSCORE & $17 \pm 7.5$ & $8.7 \pm 7.4$ & 0.001 \\
\hline STS score & $8.6 \pm 7$ & $4.2 \pm 3$ & 0.014 \\
\hline Male sex, $n(\%)$ & $7(38)$ & $12(52)$ & NS \\
\hline Diabetes, $n(\%)$ & $3(16)$ & $6(26)$ & NS \\
\hline Hypertension, $n(\%)$ & $15(83)$ & $20(87)$ & NS \\
\hline Dyslipidaemia, n (\%) & $8(44)$ & $15(65)$ & NS \\
\hline Previous AMI, n (\%) & $6(33)$ & $8(34)$ & NS \\
\hline Previous $\mathrm{PCl}, n(\%)$ & $6(33)$ & 9 (39) & NS \\
\hline Previous CABG, $n(\%)$ & $2(11)$ & $4(17)$ & NS \\
\hline CRF, n (\%) & $5(27)$ & $6(23)$ & NS \\
\hline Ischaemic aetiology, n (\%) & $6(33)$ & $8(35)$ & NS \\
\hline Non-ischaemic aetiology, n (\%) & $12(66)$ & $15(65)$ & NS \\
\hline Clips number (1), n (\%) & $10(55)$ & $12(52)$ & NS \\
\hline Clips number (2), n (\%) & $8(45)$ & $10(44)$ & NS \\
\hline Clips number (3), $n$ (\%) & $0(0)$ & $1(0.04)$ & NS \\
\hline Regurgitant volume (mL) & $54.3 \pm 17$ & $46.3 \pm 11$ & NS \\
\hline $\operatorname{EROA}\left(\mathrm{cm}^{2}\right)$ & $0.39 \pm 0.1$ & $0.33 \pm 0.1$ & NS \\
\hline Annulus diameter (mm) & $37 \pm 4.3$ & $38.6 \pm 4.5$ & NS \\
\hline LVEF \% & $29.6 \pm 8$ & $28.5 \pm 11$ & NS \\
\hline LVEDV/i $\left(\mathrm{mL} / \mathrm{m}^{2}\right)$ & $99 \pm 20$ & $91 \pm 25$ & 0.021 \\
\hline LVESV/i $\left(\mathrm{mL} / \mathrm{m}^{2}\right)$ & $69 \pm 24$ & $65 \pm 15$ & NS \\
\hline LA Volli $\left(\mathrm{mL} / \mathrm{m}^{2}\right)$ & $57 \pm 13$ & $52 \pm 21$ & NS \\
\hline RV ED area $\left(\mathrm{cm}^{2}\right)$ & $19.1 \pm 4.9$ & $16.2 \pm 4$ & 0.05 \\
\hline RV ES area $\left(\mathrm{cm}^{2}\right)$ & $12.3 \pm 3.9$ & $9.7 \pm 3.14$ & 0.026 \\
\hline RV FAC \% & $56.4 \pm 7.1$ & $38.7 \pm 9.6$ & NS \\
\hline TAPSE (mm) & $19.5 \pm 3.3$ & $21.2 \pm 3.7$ & NS \\
\hline PASp $(\mathrm{mmHg})$ & $50.6 \pm 16.5$ & $39 \pm 12.6$ & 0.014 \\
\hline GLS \% & $-6.7 \pm 4.1$ & $-6.12 \pm 2.7$ & NS \\
\hline
\end{tabular}

AMI, acute myocardial infarction; CABG, coronary artery bypass grafting; CRF, chronic renal failure; ED, end-diastolic; ES, end-systolic; EROA, effective regurgitant orifice area; FAC, fractional area change; GLS, global longitudinal strain; LA Vol/i, left atrium volume/index; LVEDV/i, left ventricular end-diastolic volume index; LVEF, left ventricular ejection fraction; LVESV/i, left ventricular end-systolic volume index; NS, not significant; PASp, pulmonary artery systolic pressure; PCI, percutaneous coronary intervention; RV, right ventricle; STS, Society of Thoracic Surgery Score; TAPSE, tricuspid annular plane excursion.

Bold values represent statistical significance of $P$ values. 
Table 4 Echocardiographic parameters at baseline and 6 months follow-up in non-rLVR group

\begin{tabular}{|c|c|c|c|}
\hline Parameters & $\begin{array}{l}\text { Baseline, } \\
\text { mean } \pm \text { SD }\end{array}$ & $\begin{array}{l}6 \text { months, } \\
\text { mean } \pm S D\end{array}$ & $P$-value \\
\hline Regurgitant volume $(\mathrm{mL})$ & $54 \pm 17$ & $29 \pm 5$ & $<0.001$ \\
\hline $\operatorname{EROA}\left(\mathrm{cm}^{2}\right)$ & $0.39 \pm 0.1$ & $0.21 \pm 0.05$ & $<0.001$ \\
\hline $\mathrm{LA}$ Vol/i $\left(\mathrm{mL} / \mathrm{m}^{2}\right)$ & $57 \pm 13$ & $53 \pm 18$ & NS \\
\hline LVEF\% & $29 \pm 8$ & $29 \pm 15$ & NS \\
\hline LVEDV/i $\left(\mathrm{mL} / \mathrm{m}^{2}\right)$ & $99 \pm 20$ & $106 \pm 35$ & 0.018 \\
\hline LVESV/i $\left(\mathrm{mL} / \mathrm{m}^{2}\right)$ & $69 \pm 24$ & $75 \pm 21$ & 0.022 \\
\hline RV ED area $\left(\mathrm{cm}^{2}\right)$ & $19 \pm 4.9$ & $21 \pm 6.8$ & NS \\
\hline RV ES area $\left(\mathrm{cm}^{2}\right)$ & $12 \pm 3.9$ & $14 \pm 6.4$ & NS \\
\hline RV FAC \% & $56 \pm 7.1$ & $34 \pm 8$ & NS \\
\hline TAPSE $(\mathrm{mm})$ & $19 \pm 3.3$ & $20 \pm 2.4$ & NS \\
\hline PASp (mmHg) & $50 \pm 16.5$ & $51 \pm 12$ & NS \\
\hline GLS \% & $-6.7 \pm 4.1$ & $-7.7 \pm 2.7$ & NS \\
\hline
\end{tabular}

ED, end-diastolic; ES, end-systolic; EROA, effective regurgitant orifice area; FAC, fractional area change; GLS, global longitudinal strain; LA Vol/i, left atrium volume/index; LVEDV/i, left ventricular end-diastolic volume index; LVEF, left ventricular ejection fraction; LVESV/i, left ventricular end-systolic volume index; NS, not significant; PASp, pulmonary artery systolic pressure; RV, right ventricle; SD, standard deviation; TAPSE, tricuspid annular plane excursion.

Bold values represent statistical significance of $P$ values.

current guidelines. ${ }^{3}$ All patients were assigned a MR severity score of 1 (mild), 2 (mild to moderate), 3 (moderate to severe), or 4 (severe), according to the quantitative measure of the effective regurgitant orifice area (EROA) and regurgitant volume. The regurgitant volume was estimated as the EROA multiplied by the velocity time integral of the regurgitant jet. Procedural success was defined as the reduction of the MR severity score to 2 or less after clip implantation. The following parameters were considered to evaluate the LV changes in size and function: LV end-diastolic and end-systolic volume indexed to body surface area (LVEDV/i and LVESV/i, respectively), and the LVEF, obtained using 3DE (full volume function). Right ventricular (RV) dimension and function and pulmonary artery systolic pressure (PASp) were also assessed according to guidelines. ${ }^{11}$ Twodimensional speckle tracking analysis with global longitudinal strain (GLS) was also obtained in all patients. LV reverse remodelling was defined as a decrease $\geq 10 \%$ in the LVESV/i at follow-up. ${ }^{12}$

\section{Reproducibility}

Intra-observer and inter-observer variability for the 3D manual measurements of LVEF and LV volumes was assessed in a sample of 10 patients. Two investigators measured blinded the same 3DEcho loops, and one investigator repeated the analysis 1 week later, blinded to the previous measurements.

\section{MitraClip procedure}

All patients were undergone to endovascular edge-to-edge MV repair as previously described. ${ }^{9,10}$ All procedures were performed using the 24-Fr MitraClip device (Abbott Vascular, Santa Clara, CA, USA). All clips were implanted under general anaesthesia and the procedures were transoesophageal echocardiography guided. Haemostasis was achieved by compression of the vein for $12 \mathrm{~h}$.
Table 5 Echocardiographic parameters at baseline and at 6 months follow-up in r-LVR group

\begin{tabular}{|c|c|c|c|}
\hline Parameters & $\begin{array}{l}\text { Baseline, } \\
\text { mean } \pm \text { SD }\end{array}$ & $\begin{array}{l}6 \text { months, } \\
\text { mean } \pm \text { SD }\end{array}$ & $P$-value \\
\hline Regurgitant volume $(\mathrm{mL})$ & $46 \pm 11$ & $25 \pm 9.3$ & $<0.001$ \\
\hline EROA $\left(\mathrm{cm}^{2}\right)$ & $0.33 \pm 0.1$ & $0.19 \pm 0.07$ & $<0.001$ \\
\hline LA Volli $\left(\mathrm{mL} / \mathrm{m}^{2}\right)$ & $52 \pm 21$ & $44.9 \pm 18$ & 0.017 \\
\hline LVEF \% & $28.5 \pm 11$ & $32 \pm 8.4$ & 0.048 \\
\hline LVEDV/i $\left(\mathrm{mL} / \mathrm{m}^{2}\right)$ & $91 \pm 25$ & $85 \pm 23$ & $<0.001$ \\
\hline LVESV/i $\left(\mathrm{mL} / \mathrm{m}^{2}\right)$ & $65 \pm 15$ & $57 \pm 20$ & $<0.001$ \\
\hline RV ED area $\left(\mathrm{cm}^{2}\right)$ & $16.2 \pm 4$ & $17.1 \pm 6$ & NS \\
\hline RV ES area $\left(\mathrm{cm}^{2}\right)$ & $9.7 \pm 3.14$ & $11.3 \pm 5$ & NS \\
\hline RV FAC \% & $38.7 \pm 9.6$ & $36.6 \pm 5.2$ & NS \\
\hline TAPSE (mm) & $21.2 \pm 3.7$ & $22.4 \pm 2.7$ & NS \\
\hline PASp $(\mathrm{mmHg})$ & $39 \pm 12.6$ & $39.9 \pm 13$ & NS \\
\hline GLS \% & $-6.12 \pm 2.7$ & $-8.5 \pm 3.3$ & $<0.001$ \\
\hline
\end{tabular}

ED, end-diastolic; ES, end-systolic; EROA, effective regurgitant orifice area; FAC fractional area change; GLS, global longitudinal strain; LA Vol/i, left atrium volume/index; LVEDV/i, left ventricular end-diastolic volume index; LVEF, left ventricular ejection fraction; LVESV/i, left ventricular end-systolic volume index; NS, not significant; PASp, pulmonary artery systolic pressure; RV, right ventricle; SD, standard deviation; TAPSE, tricuspid annular plane excursion.

Bold values represent statistical significance of $P$ values.

Patients were treated with double antiplatelet therapy after the intervention and oral anticoagulants where indicated.

\section{Statistical analysis}

Continuous variables are presented as mean \pm standard deviation and were compared using Student's $t$-test or the Mann-Whitney rank sum test for unpaired comparisons, as appropriate. The mean differences between the baseline and 6-month echocardiographic parameters are reported. The categorical variables are expressed as counts and percentages and were compared using the $\chi^{2}$ test or Fisher exact test, as appropriate. Differences were considered statistically significant when $P<0.05$. Univariable and multivariable analyses were performed with backward method to assess determinants of $r$ LVR. Variables were included in the model when $P<0.10$. Statistical analyses were performed using the Statistical Package for Social Sciences, version 23.0 (SPSS, Chicago, IL, USA). Interclass correlation coefficients (ICCs) were calculated to assess inter-observer and intra-observer agreement of 3DE measurements.

\section{Results}

\section{Baseline characteristics}

Baseline characteristics of the study population are depicted in Table 1. Mean age was $73 \pm 7.7$ years. All patients were in NYHA Class III-IV and about two-third of them had non-ischaemic cardiomyopathy. Cardiac death occurred in 3 (6\%) patients before the scheduled follow-up; 1 patient underwent cardiac surgery after 3 months because of MitraClip detachment and 41 patients had a complete 6 months follow-up echocardiogram. 

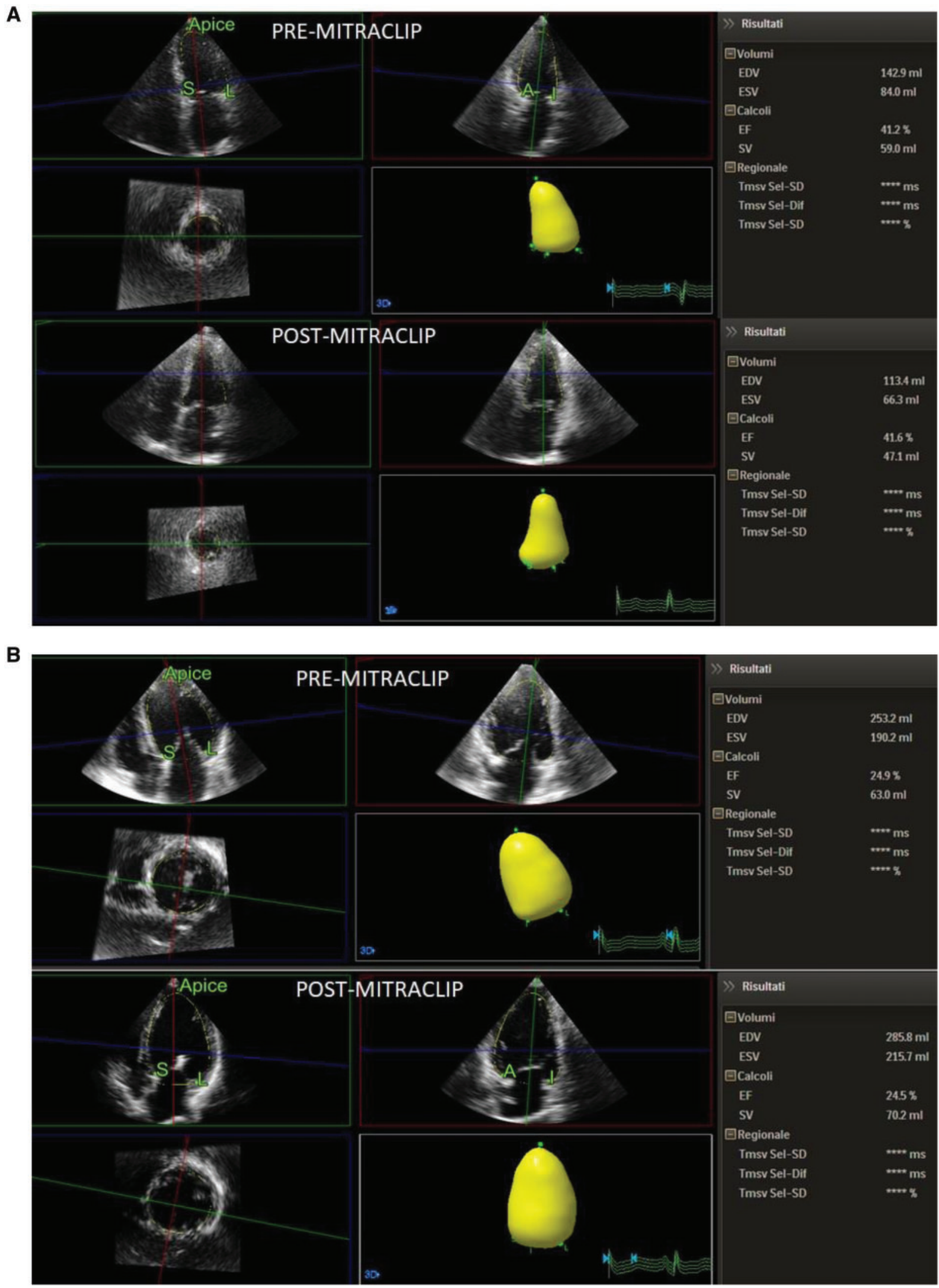

Figure 2 (A) LV volumes changes in a patient with $r$-LVR. (B) LV volumes changes in a patient without $r$-LVR. 


\begin{tabular}{|c|c|c|c|c|}
\hline \multirow[b]{2}{*}{ Variables } & \multicolumn{2}{|c|}{ Univariate analysis } & \multicolumn{2}{|c|}{ Multivariate analysis } \\
\hline & OR $(95 \% \mathrm{Cl})$ & $P$-value & OR $(95 \% \mathrm{Cl})$ & $P$-value \\
\hline STS score & $0.83(0.7-0.9)$ & 0.036 & & \\
\hline EuroSCORE & $=0.81(0.7-0.94)$ & 0.008 & & \\
\hline $\begin{array}{l}\text { LVEDV/i } \\
\quad\left(\mathrm{mL} / \mathrm{m}^{2}\right)\end{array}$ & $0.98(0.96-0.99)$ & 0.043 & & \\
\hline $\begin{array}{c}\text { RV ES area } \\
\left(\mathrm{cm}^{2}\right)\end{array}$ & $0.81(0.66-0.99)$ & 0.036 & & \\
\hline $\begin{array}{l}\text { PASp } \\
\quad(\mathrm{mmHg})\end{array}$ & $0.76(0.61-0.93)$ & 0.010 & $0.94(0.89-0.99)$ & 0.021 \\
\hline
\end{tabular}

$\mathrm{Cl}$, confidence interval; ES, end-systolic; RV, right ventricle; PASp, pulmonary artery systolic pressure; STS, Society of Thoracic Surgery Score.

Bold values represent statistical significance of $P$ values.

\section{Changes in NYHA class, MR severity and LV volumes after MitraClip implantation}

Echocardiographic parameters at baseline and at 6 months follow-up in the overall cohort of patients are depicted in Table 2. By definition, all patients had severe MR at baseline. No significant changes were observed in LV volumes and LVEF after implant. Noteworthy, a significant MR reduction was observed after implantation in all patients. Similarly, a significant improvement in NYHA functional class was detected after MitraClip implantation, as showed in Figure 1. LV reverse remodelling occurred in 23 patients (56\%), whereas 18 patients did not present reverse remodelling (non-rLVR 44\%), as showed in Table 3. At baseline, non-rLVR patients showed higher values of logistic EuroSCORE, STS score, LVEDV/i, RV end systolic area, and PASp when compared with r-LVR subgroup. In these patients, a significant increase in both LVEDV/i and LVESV/i was observed at 6 months follow-up (Table 4). On the contrary, r-LVR patients showed a significant improvement in LVEF and in GLS and a reduction in LA volume index after 6 months (Table 5). Figure 2 shows an example of volumes changes in a patient with $r$-LVR $(A)$ and a patient without $r-\operatorname{LVR}(B)$.

\section{Determinants of LV remodelling}

Table 3 compared patients with and without LVR. No significant differences in the MR aetiology and the number of clip implanted were found between the two groups. Non-significant MV stenosis and interatrial shunt was detected after the intervention in both groups. Univariable determinants of $r$-LVR were STS score $(P=0.036)$, EuroSCORE $(P=0.036)$, LVEDV/i $(P=0.043), R V$ end-systolic area $(P=0.043)$, and PASp $(P=0.010)$. On multivariable analysis, baseline PASp $[P=0.021$; odds ratio $0.94,95 \%$ confidence interval $(\mathrm{Cl}) 0.89-$ 0.99] resulted to be the only independent predictor of $r-L V R$, as showed in Table 6.

\section{Reproducibility}

Intra-observer agreement analysis showed an ICC of 0.981 $(P<0.001,95 \% \mathrm{Cl} 0.92-0.996)$ for LVEF measurements, of 0.996
Table 7 Intra- and inter-observer variability of echocardiographic measurements

\begin{tabular}{|c|c|c|}
\hline Variables & $\begin{array}{l}\text { Intra-observer } \\
\text { agreement }\end{array}$ & $\begin{array}{l}\text { Inter-observer } \\
\text { agreement }\end{array}$ \\
\hline LVEF (\%) & $\begin{array}{l}0.981(0.92-0.996) \\
P<0.001\end{array}$ & $\begin{array}{l}0.938(0.75-0.986) \\
\quad P<0.001\end{array}$ \\
\hline LVEDV/i $\left(\mathrm{mL} / \mathrm{m}^{2}\right)$ & $\begin{array}{l}0.996(0.985-0.999) \\
P<0.001\end{array}$ & $\begin{array}{l}0.994(0.736-0.999) \\
\quad P<0.001\end{array}$ \\
\hline LVESV/i $\left(\mathrm{mL} / \mathrm{m}^{2}\right)$ & $\begin{array}{l}0.998(0.992-0.999) \\
\quad P<0.001\end{array}$ & $\begin{array}{c}0.997(0.986-0.999) \\
P<0.001\end{array}$ \\
\hline
\end{tabular}

LVEDV/i, left ventricular end-diastolic volume index; LVEF, left ventricular ejection fraction; LVESV/i, left ventricular end-systolic volume index.

$(P<0.001,95 \% \mathrm{Cl} 0.985-0.999)$ for LVEDV/i measurements, and of $0.998(P<0.001,95 \% \mathrm{Cl} 0.992-0.999)$ for LVESV/i measurements.

Inter-observer agreement analysis showed an ICC of 0.938 $(P<0.001,95 \% \mathrm{Cl} 0.75-0.996)$ for LVEF measurements, of 0.994 $(P<0.001,95 \% \mathrm{Cl} 0.736-0.999)$ for LVEDV/i measurements, and of $0.997(P<0.001,95 \% \mathrm{Cl}$ 0.986-0.999) for LVESV/i measurements (Table 7).

\section{Discussion}

Secondary MR is a common finding in patients with heart failure with reduced ejection fraction and dilated $L V$, leading to progressive chamber dilatation, functional deterioration and increased mortality risk. ${ }^{13}$ MitraClip is an effective procedure to reduce the cardiac overload from severe MR. However, current criteria for subjects' selection are based on MV characteristic only, irrespective of LV and RV geometry and function.

This study showed that successful MitraClip procedure significantly reduced MR severity and improved functional NYHA class, in line with previously published data, ${ }^{14-17}$ consistently with MR reduction. However, reverse remodelling occurred, at follow-up, only in $56 \%$ of patients with severe MR and low LVEF, with a parallel improvement in GLS. Lower pulmonary pressures, smaller LV volume and lower logistic risk scores were the main determinants of reverse LV remodelling after MV repair. Previous studies showed significant benefits of MitraClip procedure in patients with preserved LVEF $^{9,10}$ and encouraging data in terms of safety and feasibility in patients with reduced LV function. ${ }^{18}$ Scandura et al. ${ }^{19}$ observed a significant improvement in LVEF and a significant $r$-LVR in a population composed of both primary and secondary MR. Rammos et al. ${ }^{20}$ demonstrated both $r$-LVR and atrial remodelling with consequent improvement in GLS after MitraClip implantation in a series of patients with an average value of LVEF of $40.5 \pm 2.5 \%$. Pleger et al. ${ }^{15-18}$ also observed a significant $r$-LVR in patients with severely reduced LVEF. ${ }^{21}$ In line with previous studies, this study confirms the good results in terms of MR reduction in the whole group of patients with low LVEF. However, percutaneous MV repair is accompanied by reverse remodelling only in specific subgroups of heart failure patients. As in our study, a significant 
improvement in both 2D and 3D GLS after MitraClip implantation was recently demonstrated ${ }^{22}$ only in patients with less RV impairment at baseline. We found that $44 \%$ of our subjects did not experience a reverse remodelling at follow-up. These patients had higher risk scores, greater LV volume, more important RV impairment and increased pulmonary pressure at baseline. Most of them had progression of LV dilatation over time. So, our data would be useful to identify a subset of patients in which MitraClip intervention will not provide the significant expected benefits and will not change the natural history of the heart failure progression and ultimately the prognosis.

\section{Limitations}

Major limitation of the study is the short follow-up observation. The absence of events during follow-up precludes showing any association between the lack of reverse remodelling and outcome. It would be interesting to extend the follow-up to look at long-term outcome and possibly further cardiac changes. Another important limitation is the small sample size of the study that could mask other differences between groups.

\section{Conclusions}

Percutaneous MV repair using MitraClip system allows reduction in MR and NYHA. However, reverse remodelling occurs few months after the intervention only in patients with less severe baseline LV dilatation, lower pulmonary pressures, and lower logistic risk score. Our findings suggest that end-stage heart failure patients, presenting before the intervention with higher LV volumes and pulmonary pressure may not benefit from the procedure at long-term follow-up. Further studies with greater number of patients and longer follow-up are needed to confirm these data.

\section{Conflict of interest: none declared.}

\section{References}

1. Rossi A, Dini FL, Faggiano P, Agricola E, Cicoira M, Frattini S. Independent prognostic value of functional mitral regurgitation in patients with heart failure. $A$ quantitative analysis of 1256 patients with ischaemic and non-ischaemic dilated cardiomyopathy. Heart 2011;97:1675-80.

2. Trichon BH, Felker GM, Shaw LK, Cabell CH, O'Connor CM. Relation of frequency and severity of mitral regurgitation to survival among patients with left ventricular systolic dysfunction and heart failure. Am J Cardiol 2003;91:538-43.

3. Baumgartner H, Falk V, Bax JJ, De Bonis M, Hamm C, Holm PJ et al.; ESC Scientific Document Group. 2017 ESC/EACTS Guidelines for the management of valvular heart disease. Eur Heart J 2017;38:2739-91.

4. Song BG, On YK, Jeon ES, Kim DK, Lee SC, Park SW. Atrioventricular reverse remodeling after valve repair for chronic severe mitral regurgitation: 1-year follow-up. Clin Cardiol 2010;33:630-7.

5. Crestanello JA. Surgical approach to mitral regurgitation in chronic heart failure: when is it an option? Curr Heart Fail Rep 2012;9:40-50.
6. Feldman T, Wasserman HS, Herrmann HC, Gray W, Block PC, Whitlow P et al. Percutaneous mitral valve repair using the edge-to-edge technique: six month results of the EVEREST phase I clinical trial. J Am Coll Cardiol 2005;46:2134-40.

7. Tamburino C, Ussia GP, Maisano F, Capodanno D, La Canna G, Scandura S et al. Percutaneous mitral valve repair with the MitraClip system: acute results from a real world setting. Eur Heart J 2010;31:1382-9.

8. Feldman T, Foster E, Glower DG, Kar S, Rinaldi MJ, Fail PS et al. EVEREST ॥ Investigators. Percutaneous repair or surgery for mitral regurgitation. N Engl J Med 2011:364:1395-406.

9. Whitlow PL, Feldman T, Pedersen WR, Lim DS, Kipperman R, Smalling R et al. EVEREST II Investigators. Acute and 12-month results with catheter-based mitral valve leaflet repair: the EVEREST II (Endovascular Valve Edge-to-Edge Repair) High Risk Study. J Am Coll Cardiol 2012;59:130-9.

10. Feldman T, Kar S, Rinaldi M, Fail P, Hermiller J, Smalling $R$ et al. EVEREST Investigators. Percutaneous mitral repair with the MitraClip system: safety and midterm durability in the initial EVEREST (Endovascular Valve Edge-to-Edge Repair Study) cohort. J Am Coll Cardiol 2009;54:686-94.

11. Lang RM, Badano LP, Mor-Avi V, Afilalo J, Armstrong A, Ernande L et al. Recommendations for cardiac chamber quantification by echocardiography in adults: an update from the American Society of Echocardiography and the European Association of Cardiovascular Imaging. Eur Heart J Cardiovasc Imag 2015;16:233-70.

12. Funaro S, La Torre G, Madonna M, Galiuto L, Scarà A, Labbadia A et al. Incidence, determinants, and prognostic value of reverse left ventricular remodelling after primary percutaneous coronary intervention: results of the Acute Myocardial Infarction Contrast Imaging (AMICl) multicenter study. Eur Heart J 2009;30:566-75

13. Patel JB, Borgeson DD, Barnes ME, Rihal CS, Daly RC, Redfield MM. Mitral regurgitation in patients with advanced systolic heart failure. J Card Fail 2004;10: 285-91.

14. Franzen $O$, van der Heyden J, Baldus S, Schlüter M, Schillinger W, Butter $C$ et al. MitraClip therapy in patients with end-stage systolic heart failure. Eur J Heart Fail 2011;13:569-76.

15. Barth S, Hautmann MB, Kerber S, Gietzen F, Schade A, Deneke T et al. Hemodynamic improvement at three months follow-up after Mitraclip treatment in end-stage heart failure patients with functional mitral regurgitation. J Heart Valve Dis 2016;25:475-82.

16. Pleger ST, Chorianopoulos E, Krumsdorf U, Katus HA, Bekeredjian R Percutaneous edge-to-edge repair of mitral valve regurgitation as a bail-out strategy in critically ill patients. J Invasive Cardiol 2013;25:69-72.

17. Pleger ST, Mereles D, Schulz-Schönhagen M, Krumsdorf U, Chorianopoulos E, Rottbauer $W$ et al. Acute safety and 30-day outcome after percutaneous edgeto-edge repair of mitral regurgitation in very high-risk patients. Am J Cardiol 2011; 108:1478-82.

18. Franzen O, Baldus S, Rudolph V, Meyer S, Knap M, Koschyk D et al. Acute outcomes of MitraClip therapy for mitral regurgitation in high-surgical-risk patients: emphasis on adverse valve morphology and severe left ventricular dysfunction. Eur Heart J 2010;31:1373-81.

19. Scandura S, Ussia GP, Capranzano P, Caggegi A, Sarkar K, Cammalleri V et al. Left cardiac chambers reverse remodeling after percutaneous mitral valve repair with the MitraClip system. J Am Soc Echocardiogr 2012;25: 1099-105

20. Rammos C, Zeus T, Blazer J, Veulemans V, Hellhammer K, Niebel S et al. Left atrial and left ventricular function and remodeling following percutaneous mitral valve repair. J Heart Valve Dis 2016;25:309-19.

21. Pleger ST, Schulz-Schönhagen M, Geis N, Mereles D, Chorianopoulos E, Antaredja $M$ et al. One year clinical efficacy and reverse cardiac remodelling in patients with severe mitral regurgitation and reduced ejection fraction after MitraClip implantation. Eur J Heart Fail 2013;15:919-27.

22. Vitarelli A, Mangieri E, Capotosto L, Tanzilli G, D’Angeli I, Viceconte N et al. Assessment of biventricular function by three-dimensional speckle-tracking echocardiography in secondary mitral regurgitation after repair with the MitraClip system. J Am Soc Echocardiogr 2015;28:1070-82. 